\title{
New possibilities of metal corrosion inhibition by organic heterocyclic compounds
}

\author{
Yu. I. Kuznetsov \\ A. N. Frumkin Institute of Physical Chemistry and Electrochemistry, Russian Academy of \\ Sciences, Leninskii pr. 31, Moscow, 119071 Russian Federation \\ E-mail:kuznetsov@ipc.rssi.ru
}

\begin{abstract}
It is shown that many heterocyclic organic compounds, e.g., various azoles, are capable of adsorption on metals with formation of strong bonds with the surface. The approach based on the linear free energy relationship (LFER) principle offers a description of the efficiency of corrosion inhibition by these compounds and provides an understanding of the nature of chemical bonds formed by an organic inhibitor with a metal that needs to be protected. Knowledge of the specifics of interaction between azoles and metal surfaces can be helpful in choosing a promising corrosion inhibitor for drastic conditions, for example, in chemical mechanical planarization slurries where simultaneous mechanical polishing and electrochemical dissolution of the surface usually occur. Corrosion inhibition of steel at high temperatures $\left(\geq 150^{\circ} \mathrm{C}\right)$ in mineral acid solutions is yet another example of a new successful use of azoles. It is demonstrated that new possibilities for improving the anticorrosive protection of metals are provided not only by using mixtures of some azoles with carboxylate-type organic corrosion inhibitors but also by constructing bilayer nanocoatings from aqueous solutions. For example, strong adsorption of small amounts of rather an exotic compound, dimegin (disodium salt of deuteroporphyrin), not only promotes the passivation of iron in neutral aqueous solutions but also impedes the local depassivation of the metal. Furthermore, it offers wide possibilities for further improvement of adsorption of other heterocyclic chemical compounds due to preliminary modification of the metal surface even by a small dimegin concentration.
\end{abstract}

Key words: corrosion inhibitors, linear free energy relationship, azoles, adsorption.

Received: July 15, 2012.

doi: 10.17675/2305-6894-2012-1-1-003-015

One of the most important groups of corrosion inhibitors (hereinafter inhibitors) includes heterocyclic compounds. The interest in these compounds has not abated for over half a century. Meanwhile, over the last decade, not only the specific features of the mechanism have been studied in more detail for known inhibitors of this type, but also the range of objects that can be protected has been expanded and new efficient inhibitors and protection 
methods for various metals and alloys have appeared that are promising for modern industries, including nanotechnologies.

An important position among heterocyclic inhibitors belongs to various azoles [1]. In many cases it can be explained by the specifics of their chemical structure. It was shown a long time ago that if the inhibitor molecule contains a second reaction center, then, under certain conditions, it may form chelates with the metal being protected, resulting in a considerable enhancement in stability of the protective layer on the surface. Strengthening of the bond with the metal can be achieved not only due to the bond with the heteroatom but also due to $\pi$-electronic interaction of the aromatic ring with the surface. For example, this assumption was used to explain the ability of benzimidazole and its derivatives to form a thin hardly soluble film of a complex with the metal, which protected copper and zinc in aqueous phosphate solutions at $\mathrm{pH} 11.4$ [2].

In this case we used the linear free energy relationship (LFER) principle [3] which presents the base of the energy assessment of the inhibitor reactivity. According to LFER, not only the logarithm of the rate constant $k$ (and the equilibrium constant $K$ for a reversible reaction) but also their relative change can provide a measure of the reactivity of chemical compounds. In the well known Hammett equation

$$
\lg \left[k_{\mathrm{R}} / k_{\mathrm{H}}\right]=\rho \sigma \text { or } \lg \left[K_{\mathrm{R}} / K_{\mathrm{H}}\right]=\rho \sigma,
$$

where indexes " $\mathrm{H}$ " and " $\mathrm{R}$ " refer to unsubstituted and substituted substances, respectively, $\sigma$ is the characteristic of substituent $R$ and $\rho$ is a reaction parameter which is taken as 1.0 for the standard series of the dissociation of substituted benzoic acids. Usually $\sigma_{\mathrm{H}}=0$ for a hydrogen atom in an unsubstituted substance, $\sigma>0$ for electron-accepting $R$, and $\sigma<0$ for electron-donor $R$. The $\rho$ value depends on the nature of the reaction under study and also on the reaction conditions. Without going too deeply into the problem (which has been considered in detail in specialist literature), one can point out that the LFER principle was applied to the corrosion inhibition in many works $[2,4,5]$. In these cases, equation (1) is transformed to:

$$
\lg \left[\gamma_{\mathrm{R}} / \gamma_{\mathrm{H}}\right]=\rho \sigma,
$$

where $\gamma$ is the coefficient of corrosion retardation of the metal by the inhibitor (or $\gamma_{\mathrm{an}}=$ $i_{\text {blank }} / i_{\text {in }}$ in the case of the anodic dissolution at a constant electrode potential, $E=$ const).

As one can see from the dependence of $\lg \gamma_{\text {an }}$ on the inductive $\sigma_{\mathrm{I}}$-constant of the $R$ in benzimidazoles (BIs) [6] or in 5(6)-nitro-2R-BIs [7], electron-accepting $R$ improved the protection of copper but decreased that of zinc (Fig. 1). On the other hand, an increase in electron-donor properties of the $R$ weakened the inhibition of copper dissolution but increased it for zinc. However, in both cases $\lg \gamma_{\text {an }}$ correlated well with the inductive $\sigma_{I^{-}}$ constants of the $R$. 

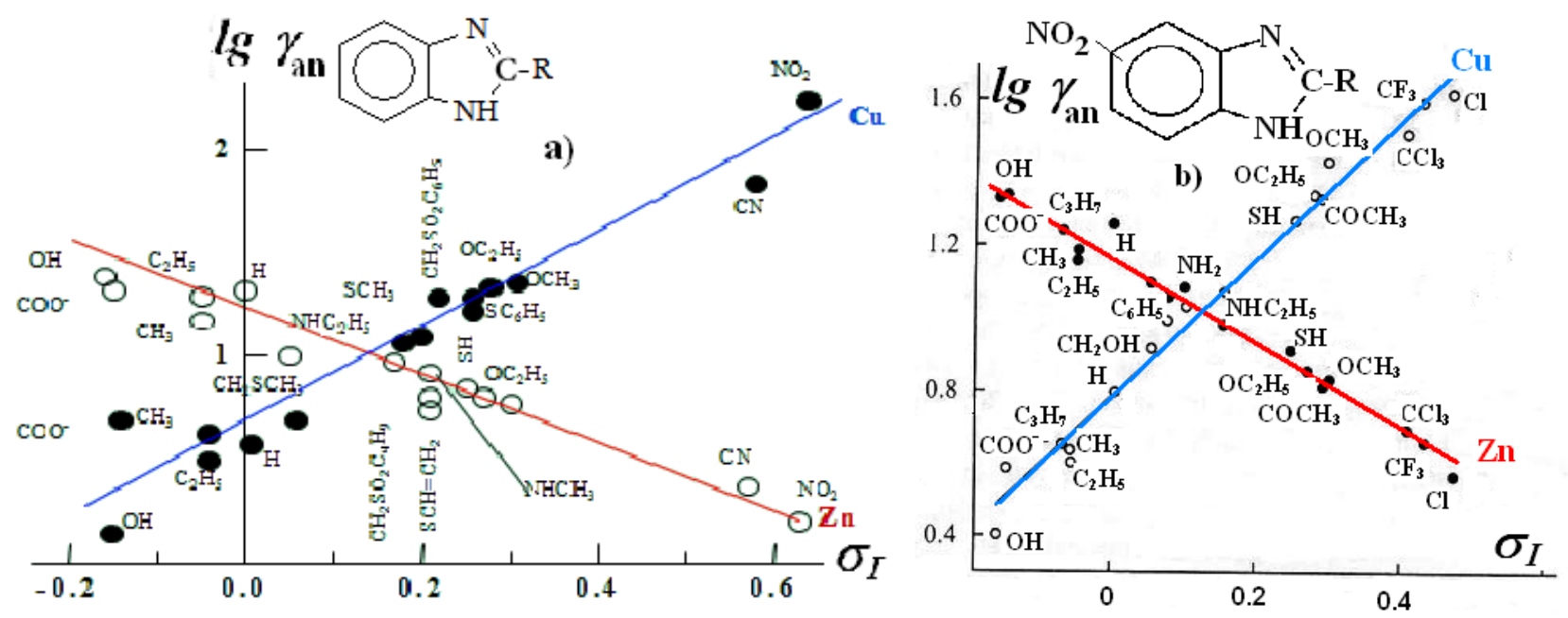

Fig. 1. The dependence of $\lg \gamma_{\mathrm{an}}$ on the $\sigma_{\mathrm{I}}$-constants of the $R$ in $\mathrm{BI}(a)$ and 5(6)-nitro-2-Rsubstituted BIs on the anodic dissolution of copper and zinc in $0,5 \mathrm{M}$ phosphate solution at $\mathrm{pH}$ 11.4. Inhibitor concentration: $C_{\mathrm{in}}=5 \cdot 10^{-4} \mathrm{M}(\mathrm{Cu})$ and $5 \cdot 10^{-3} \mathrm{M}(\mathrm{Zn}) ; E=0.14 \mathrm{~V}(\mathrm{Cu})$ or $-1.0 \mathrm{~V}(\mathrm{Zn})$

The different effects of the chemical structure of BIs on the protection of these metals can be explained by the ability of copper and zinc to form chemical bonds in their complexes. In a covalent $\sigma$ bond, only ligands are donors of electrons and the metal cation is the acceptor. An increase in electron density at the reaction centre of BIs, in which the "pyridine" and "pyrrole" nitrogens are mutually equivalent because of a rapid proton exchange, should be capable of strengthening the $\sigma$ bonds and increasing the effectiveness of inhibition. This is the case for the protection of zinc. On the other hand, copper, as a consequence of its low ionization potential and high electronegativity, is capable of acting as an electron donor and forming a common molecular orbital with $\pi$-like electrons of the ligand. Thus, a decrease in the electron density at the reaction center of the BI improves the protection of copper. The value of the minimum concentration for inhibition in $\mathrm{mol} \mathrm{L}^{-1}$, $C_{\min }$, as determined from long-term corrosion tests, is also found to depend on the nature of the $R$

$$
\begin{aligned}
& \mathrm{Cu}: \lg C_{\min }=-2.55-2.21 \sigma_{1} \quad r=0.92 \\
& \mathrm{Zn}: \lg C_{\min }=-2.65+3.30 \sigma_{1} \quad r=0.92
\end{aligned}
$$

(where $r$ is the correlation coefficient). Evidently, in both cases the effectiveness of the inhibitors depends on the stability of the complexes that are formed, which will be determined by the nature of the metal-ligand bond that is different for zinc and copper complexes. Unfortunately, the stability constants, $K_{s}$, of the appropriate complexes are not known (apart from those of benzimidazole), and therefore it remains uncertain whether a still more precise prediction of the inhibitive action of azoles could be made if $K_{s}$ values were known. 
Analogous dependences were observed by us with 2-substituted benzothiazoles (BT) [6] (Fig. 2). Here an increase in the electron density on the reaction center in BT strengthens the $\sigma$-bond in protective zinc complexes and increases the inhibitor efficiency. In contrast, the copper protection is enhanced by electron-acceptor $R$. These examples show the need for all round study of the mechanism of corrosion inhibition by heterocyclic compounds and the important place in this belongs to investigations of the "chemical structure-property" function. From these considerations, it follows that of the BTs studied, 2-mercaptobenzothiazole (MBT, trade name "captax") is a very effective inhibitor of copper corrosion in phosphate solutions.

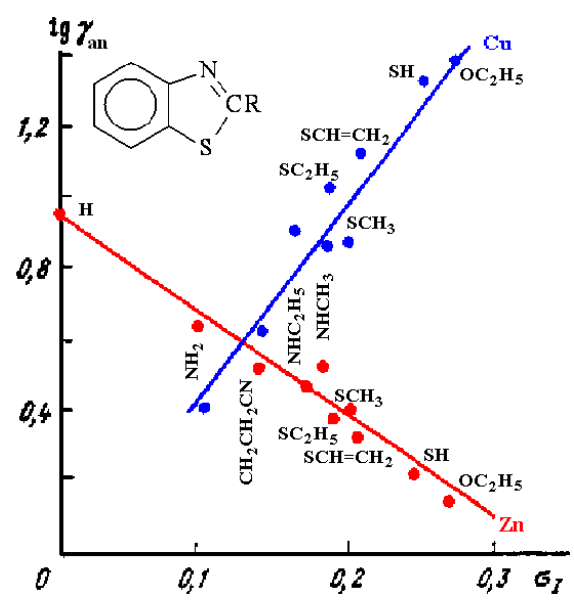

Fig. 2. The dependence of $\lg \gamma_{\text {an }}$ on the inductive $\sigma_{\mathrm{I}}$-constants of the $R$ in benzothiazoles on the anodic dissolution of copper and zinc in $0.5 \mathrm{M}$ phosphate solution at $\mathrm{pH} 11.4 . C_{\mathrm{in}}=0.5 \mathrm{mM}$ $(\mathrm{Cu})$ and $1.0 \mathrm{mM}(\mathrm{Zn}) ; E=0.14 \mathrm{~V}(\mathrm{Cu})$ and $-1.0 \mathrm{~V}(\mathrm{Zn})$

Even in [8-10] it was shown that on a surface of copper immersed in an acidic or neutral aqueous solution containing MBT, a thin film of complex $\mathrm{Cu}(\mathrm{I})-\mathrm{MBT}=1: 1$ is formed. Since phosphate solutions are suggested as media for chemical mechanical planarization of copper in manufacturing integrated circuits [11], the adsorption of MBT on copper surface from these solutions was studied in our lab [12]. It should be noted that according to [13], MBT is very efficient in suppressing the copper oxide formation covering almost completely a copper surface in $800 \mathrm{~s}$. This property of MBT is very important, but it remained unclear whether MBT is capable of preventing the formation of $\mathrm{Cu}$ (II) phosphate.

Various methods were applied to study the interaction of MBT with copper surface, from electrochemical (in situ) to physical ones, such as X-ray photoelectron spectroscopy (XPS) requiring the sample to be removed from a test solution (ex situ). As is seen from the anodic polarization curves of copper in phosphate buffer solution with pH 7.4 (Fig. 3), MBT molecules adsorb on copper to form a protective barrier that can completely suppress the anodic dissolution of the electrode. It can be observed that at $C_{\mathrm{MBT}}<0.7 \mathrm{mmol} / 1$ the anodic current peak does not decrease because of concurrence in adsorption of MBT and 
phosphate (and its copper salt). However, upon reaching $C_{\mathrm{MBT}}=0.7 \mathrm{mmol} / \mathrm{l}$, a passive layer is formed and blocks the active sites of dissolution. The second peak of the anodic current may correspond to the electrochemical oxidation of MBT to 2,2'-dibenzothiazole disulphide [14].

In our lab L.P. Kazansky and I.A. Selyaninov studied the composition of the films formed by MBT on copper surface using XPS and X-ray induced Auger spectroscopy [12]. They found that MBT is tightly bound to the copper surface because rigorous washing in ultrasonic bath does not remove MBT complex. In blank phosphate solution after exposure of copper samples at corrosion potential $E_{c o r}$ for $30 \mathrm{~min}$, the surface layer contained $\mathrm{Cu}\left(\mathrm{HPO}_{4}\right)$ precipitated as islands on the substrate, leading to non-uniform charging of various sites on the copper surface. Besides, the spectrum reveals a peak at $932.6 \mathrm{eV}$, which is characteristic of metallic copper, and $\mathrm{Cu}_{2} \mathrm{O}$.

Exposure of the samples at $E_{\text {cor }}$ in a solution containing $<0.25 \mathrm{mmol} / 1 \mathrm{MBT}$ resulted in a layer of copper (II) phosphate on the surface, together with trace amounts of MBT. On increase in $C_{\mathrm{MBT}}$ to $0.70-2.5 \mathrm{mmol} / 1$, a film of the complex whose thickness only slightly depends on the MBT concentration grows. To follow the growth of the surface film, an analysis of the samples exposed for various times in a solution containing $2.5 \mathrm{mmol} / \mathrm{l} \mathrm{MBT}$ has been carried out. Even small amounts of MBT in phosphate solution prevent copper(II) formation. It completely disappears from the surface after $30 \mathrm{~min}$ exposure of electrode at $E=0.3 \mathrm{~V}$ in a solution containing $2.5 \mathrm{mmol} / 1 \mathrm{MBT}$ (without MBT the layer thickness of copper(II) phosphate is more than $10 \mathrm{~nm}$ ). The thickness of the film of the complex grown on a copper surface at $E_{\text {cor }}$ depends on the logarithm of exposure time of the electrode in a phosphate solution (Fig. 4). As may be seen from the same plot, $\mathrm{Cu}_{2} \mathrm{O}$ also disappears.

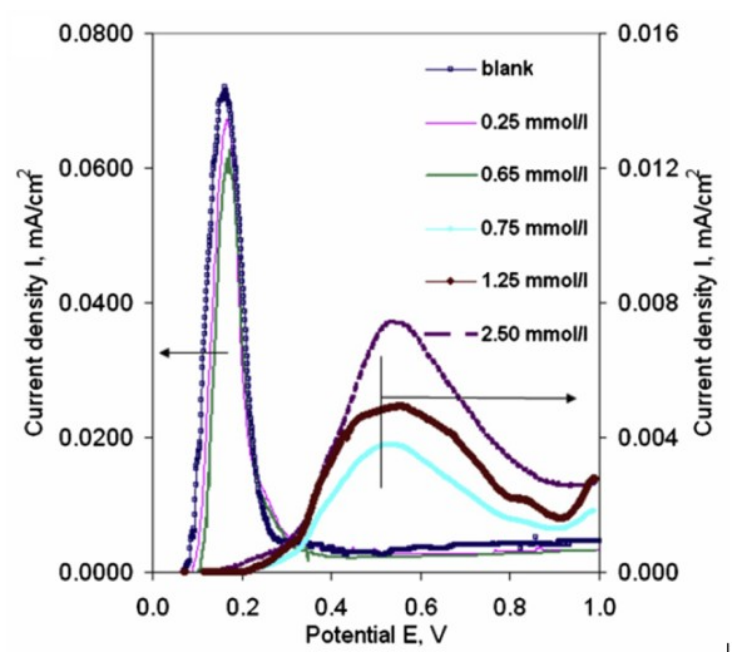

Fig. 3. Anodic polarization curves of copper in $0.5 \mathrm{M}$ phosphate solution without and with MBT. 


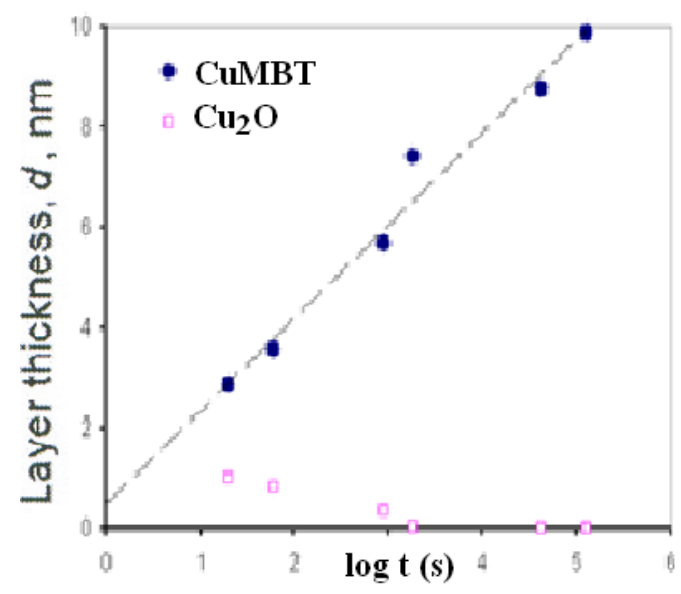

Fig. 4. Dependence of the thickness of the layers of the complex and $\mathrm{Cu}_{2} \mathrm{O}$ on exposure time.

As is evident from the foregoing, introduction of strong electron-accepting $R$ in $\mathrm{BI}$ improved the protection of copper in phosphate solutions. 4,5-Dinitrobenzimidazole (4,5DNBA) studied by us [15] is yet another example of an inhibitor that can be used in chemical mechanical planarization (CMP) slurries. CMP is usually achieved by simultaneous mechanical polishing and electrochemical dissolution of the surface that is undergoing planarization. The efficiency of CMP is basically determined by the chemical composition of the electrolyte used in the planarization process. Copper dissolution in CMP occurs only at the mechanically activated sites of the treated surface, i.e., the surface sites where the passive film was mechanically removed by the pad and abrasive particles. One of the main requirements for the electrolyte used in CMP is to provide fast passivation for the metal being planarized, so that the surface sites which are not in direct contact with the pad and abrasive particles would remain passive.

Without DNBA, the anodic polarization of copper from $E_{\text {cor }}=160 \mathrm{mV}$ results in a rapid increase in the anodic current up to $250 \mu \mathrm{A} / \mathrm{cm}^{2}$ (Fig. 5). After that, the anodic current rapidly decreased and remained low in a wide potential range indicating copper passivity. 4,5-DNBA significantly suppressed anodic current in the active-passive transition potential range, so that the active copper dissolution peak completely disappeared in the anodic curve. One can also see a substantial suppression of the cathodic current in phosphate solution in the presence of 4,5-DNBA. 


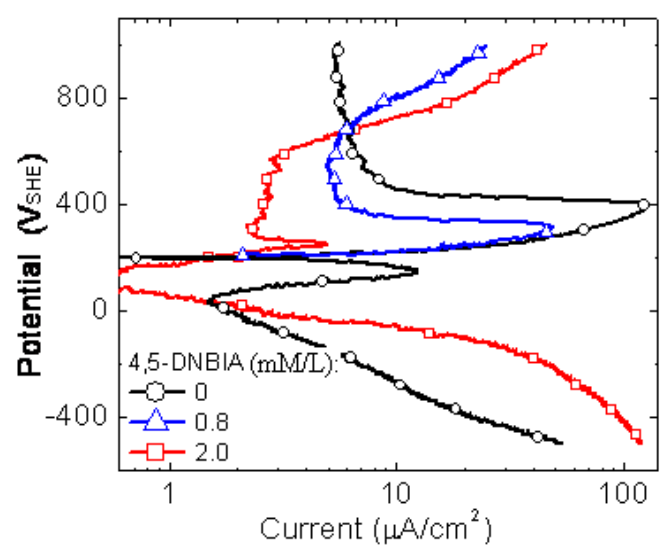

Fig. 5. Polarization curves of $\mathrm{Cu}$ in acidic water-ethanol phosphate solution $(100 \mathrm{~g} / 1$ ethanol, $\mathrm{pH} 4.00$ ) without and with 4,5-DNBA.

In order to determine the rate of protective film formation, copper specimens were exposed in an acidic phosphate solution ( $\mathrm{pH} 4.06$ ) containing 4,5-DNBA at $E=0.45 \mathrm{~V}$ (Fig. 6). One can see that exposure to the inhibitor containing solution was accompanied by a rapid reduction in anodic current. The higher the 4,5-DNBA content the more rapid reduction in anodic current was detected. Short exposure of a copper specimen in a $10 \mathrm{mmol} / 1$ 4,5-DNBA solution results in a significant decrease in anodic current. For comparison the effect of BTA on the cathodic current of copper is presented. One can see that a protective film is formed much more slowly in the presence of BTA than with 4,5DNBA, especially at initial stages of exposure.

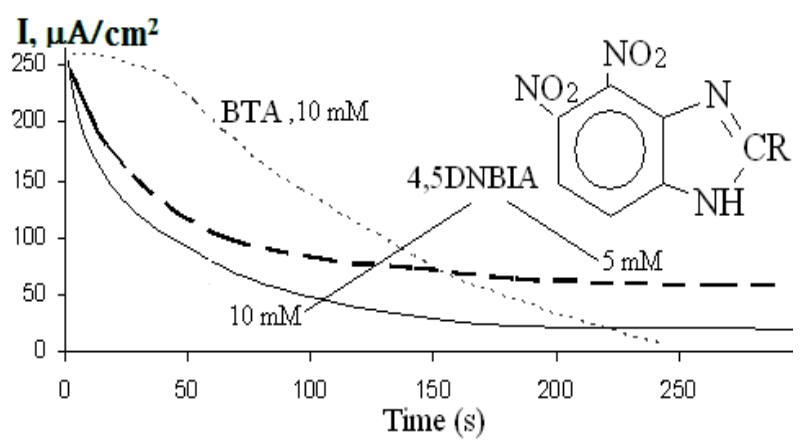

Fig. 6. Current decay curves obtained from a potentiostatically polarized copper electrode at $E=0.45 \mathrm{~V}$ in acidic phosphate solutions. BTA and 4,5-DNBA were added after the application of the anodic potential.

The other inhibitor group, which appears to be even more abundant, includes triazoles. A lot of quite efficient inhibitors have been found among substituted triazoles over the last decade. 5-Chloro-BTA is one of them [16-19]. Its adsorption from neutral aqueous solutions was studied by us by ellipsometric and XPS techniques on mild steel, copper, zinc and nickel surfaces. 
As an illustration let us consider the effect of 5-chloro-BTA on the anodic dissolution of mild steel in borate buffer ( $\mathrm{pH}$ 7.4) containing $0.01 \mathrm{M} \mathrm{NaCl}$ [17]. As can be seen from Fig. 7 , even in the presence of as little as $1.0 \mathrm{mmol} / 1$ 5-chloro-BTA, $i_{\mathrm{p}}$ decreases from 83 to $18 \mu \mathrm{A} / \mathrm{cm}^{2}$. At $C_{\text {in }}=2 \mathrm{mmol} / 1,5$-chloro-BTA passivates steel, although it cannot stabilize its passive state. To hinder local depassivation by the inhibitor, $C_{\mathrm{in}}>3 \mathrm{mmol} / \mathrm{l}$ is required. The capability of 5-chloro-BTA to inhibit the dissolution of steel may be associated with adsorption on the electrode surface. In connection with this, it was of interest to study the adsorption of the inhibitor on passive steel at $E=0.2 \mathrm{~V}$ from borate buffer (Fig. 8).

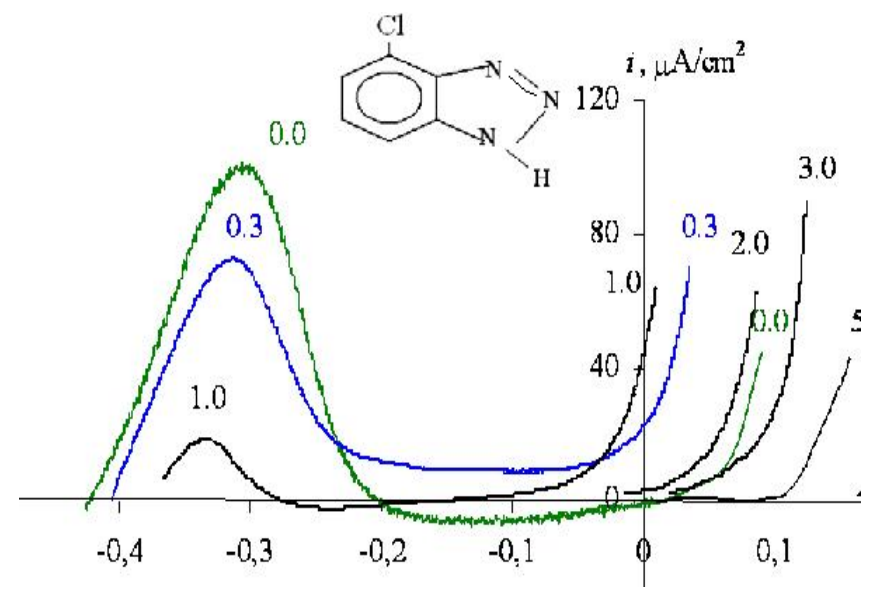

Fig. 7. Anodic polarization curves of mild steel in borate buffer ( $\mathrm{pH} 7.4)$ containing $0.01 \mathrm{M}$ $\mathrm{NaCl}$ and 5-chloro-BTA (mmol/l).

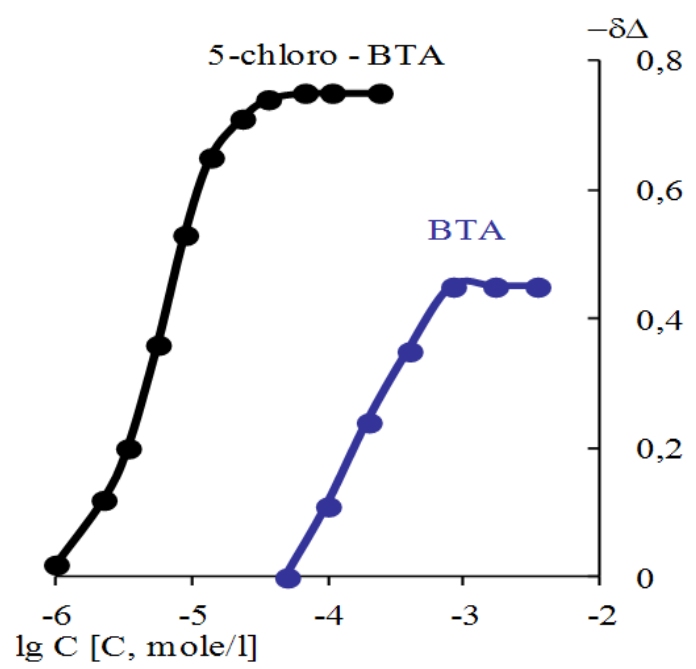

Fig. 8. Change in ellipsometric angle $\Delta \delta$ as a function of logarithm of inhibitor concentration on mild steel oxidized at $E=0.2 \mathrm{~V}$.

We assumed that reaching the plateau for the plot of changes in ellipsometric angle $\left(\delta \Delta=\Delta-\Delta_{0}\right.$, where $\Delta$ is the current angle value, $\Delta_{0}$ relates to the filmless surface, i.e., 
measured in the absence of the adsorption film) versus $\lg C$ corresponds to the degree of coverage $\theta=1.0$. The adsorption isotherm obtained can be adequately described by the Frumkin equation

$$
B C=[\theta /(1-\theta)] \cdot \exp (-2 \cdot a \cdot \theta),
$$

where $B=[1 / 55.5] \exp \left(-\Delta G_{\mathrm{A}}^{0} / R T\right)$ is the experimentally measured adsorption constant from which the value of the adsorption free energy can be calculated, and $a$ is the attraction constant. The value $a>0$ indicates an attractive interaction between the adsorbed particles. Conversely, $a<0$ shows a repulsive interaction between them.

As one might expect, 5-chloro-BTA begins to adsorb at much lower $C_{\text {in }}$ than BTA. It is not surprising that the value of $\left(-\Delta G_{\mathrm{A}}^{0}\right)$ for 5-chloro-BTA is higher than that for BTA: 37.4 and $26.5 \mathrm{~kJ} / \mathrm{mol}$, respectively. Recently we showed [20] that a mixture of BTA with the sodium salt of flufenamic acid (SFA) $\left[3-\left(\mathrm{CF}_{3}\right) \mathrm{C}_{6} \mathrm{H}_{4} \mathrm{NH}\right] \mathrm{C}_{6} \mathrm{H}_{4} \mathrm{COONa}$ demonstrated better adsorption on mild steel and a higher protective action than the components taken separately. Since development of inhibitor mixtures that protect metals better than either of their components is a hot topic, we studied the joint adsorption of 5-chloro-BTA with SFA as well. A combination of 5-chloro-BTA with SFA is adsorbed on oxidized steel surface much better than not only its components, but also an analogous mixture of BTA with SFA (Fig. 9). Its conditional adsorption isotherm is adequately described by equation (4) with $a=1.72 \pm 0.23$ and $\left(-\Delta G_{\mathrm{A}}^{0}\right)=58.5 \pm 2.9 \mathrm{~kJ} / \mathrm{mol}$ (for the composition BTA with SFA, the parameters are as follows: $a=1.93 \pm 0.14$ and $\left.\left(-\Delta G_{\mathrm{A}}^{0}\right)=53.5 \pm 2.7 \mathrm{~kJ} / \mathrm{mol}\right)$. The highest effectiveness of the mixture was confirmed by electrochemical studies (Fig. 10).

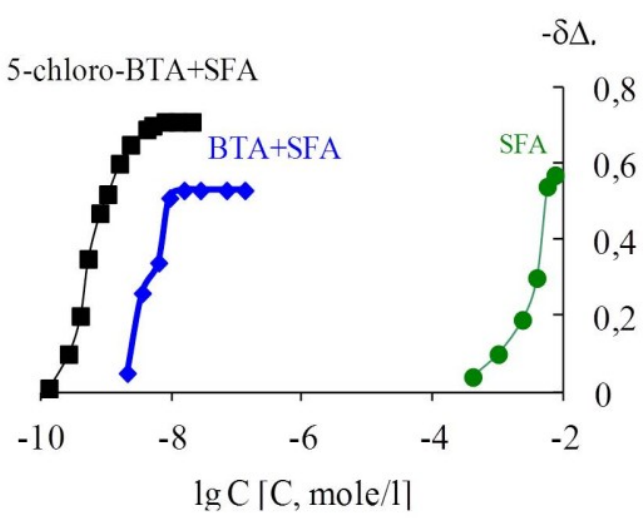

Fig. 9. Change in ellipsometric angle $\delta \Delta$ as a function of logarithm of inhibitor concentration on mild steel surface oxidized at $E=0.2 \mathrm{~V}$. 


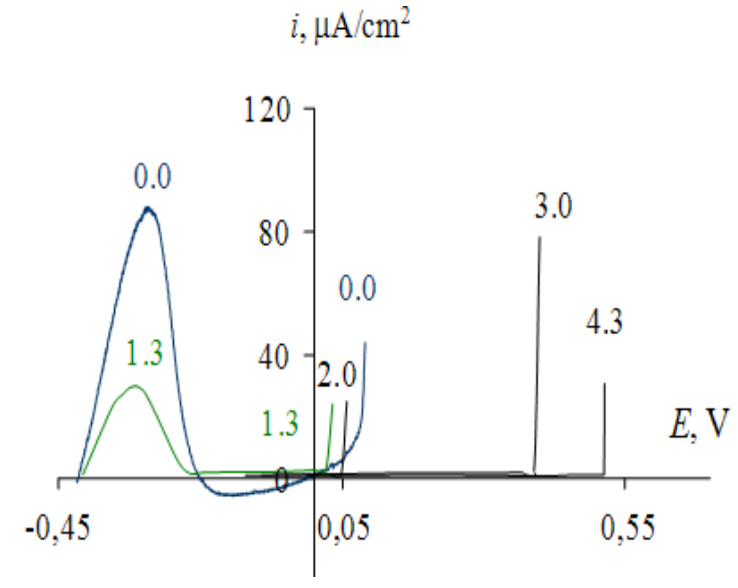

Fig. 10. Anodic polarization curves of mild steel in borate buffer (pH 7.4) containing $0.01 \mathrm{M}$ $\mathrm{NaCl}$ and a mixture of 5-chloro-BTA with SFA (mmol/1).

As is evident from comparison of the anodic polarization curves (Fig. 7 and 10), the 5-chloro-BTA + SFA mixture stabilizes the passivity at lower concentrations than 5chloro-BTA itself. Earlier we have shown [20] that $E_{\mathrm{pt}}$ value in the same background solution containing BTA $+\mathrm{SFA}$ at $C_{\text {in }}=5.0 \mathrm{mmol} / 1$ is about $0.28 \mathrm{~V}$, i.e., is much lower than $E_{\mathrm{pt}}$ in the presence of the new composition even at $C_{\mathrm{in}}=4.3 \mathrm{mmol} / \mathrm{l}$.

XPS was used to obtain additional information about the composition and thickness of layers formed on the surface of mild steel during exposure of samples in solutions of the new inhibitor. SFA and 5-chloro-BTA are convenient molecules for examination of adsorption on a surface since the compounds contain heteroatoms N, F or Cl. Earlier we showed by angle resolved XPS [21] that SFA anions preferentially adsorb on mild steel surface with oxygen of the carboxyl group forming the coordination bonds with iron cations and the whole molecule is in upright position with $\mathrm{CF}_{3}$ groups forming the utmost surface layer. It was found that if electrode washing is carried out in an ultrasonic bath, the thickness of the calculated SFA layer is close to one found in the ellipsometric studies carried out in situ at $E=$ const using a standard McCrackin program [22] (Table 1).

Table 1 Thickness of overlayers $(\mathrm{nm})$ on mild steel samples exposed in a borate solution containing the corrosion inhibitors.

\begin{tabular}{ccc}
\hline \multirow{2}{*}{ Inhibitor } & \multicolumn{2}{c}{ Method of calculating thickness, $\mathbf{n m}$} \\
\cline { 2 - 3 } & XPS & Ellipsometry \\
\hline SFA & $0.9 \pm 0.1$ & $1.1 \pm 0.1$ \\
5-chloro-BTA & $0.4 \pm 0.1$ & $0.7 \pm 0.1$ \\
5-chloro-BTA + SFA & $0.7 \pm 0.3$ & $0.8 \pm 0.1$ \\
\hline
\end{tabular}


Analogous results were obtained with 5-chloro-BTA and a mixture of the inhibitors [17]. It was also found that, if adsorption was performed from a solution of their mixture, anions SFA and 5-chloro-BTA acquired an almost vertical orientation on a steel surface.

Triazoles have been studied and used as inhibitors of metal corrosion in aqueous solution of acids for a long time [1,23]. Particular attention has been given to inhibition of corrosion of metals at elevated temperatures $\left(>120^{\circ} \mathrm{C}\right)$ since the range of inhibitors recommended for steel protection at higher temperatures is appreciably narrow. A complex mixture containing an acetylenic alcohol, an $\mathrm{N}$-containing product of amine condensation with formaldehyde, $\mathrm{KI}$ and $\mathrm{SnCl}_{2}$ or $\mathrm{CrCl}_{3}$ was proposed for these conditions [24]. Later, W. Frenier [25] recommended substituting toxic acetylenic compounds by harmless cinnamaldehyde.

A high-temperature inhibitor of acid corrosion based on triazole (Triazole A) was developed and studied in our lab [26]. Its unique feature is that Triazole A can be used as an individual compound to protect steel at elevated temperatures, e.g., in $2.0 \mathrm{M} \mathrm{H}_{2} \mathrm{SO}_{4}$ (Fig. 11).

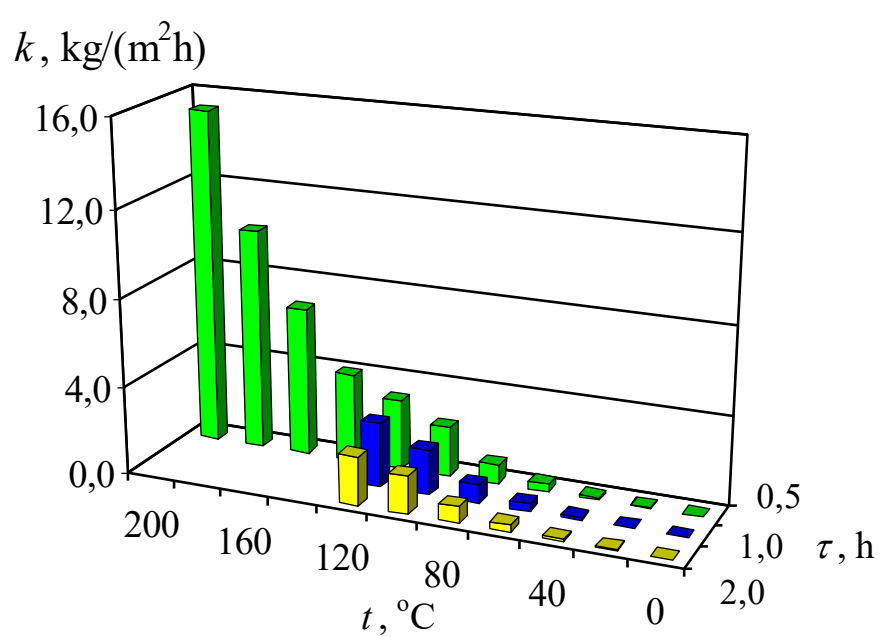

Fig. 11a. Dependence of corrosion rate of mild steel on temperature in $2.0 \mathrm{M} \mathrm{H}_{2} \mathrm{SO}_{4}$ at various durations of experiment. 


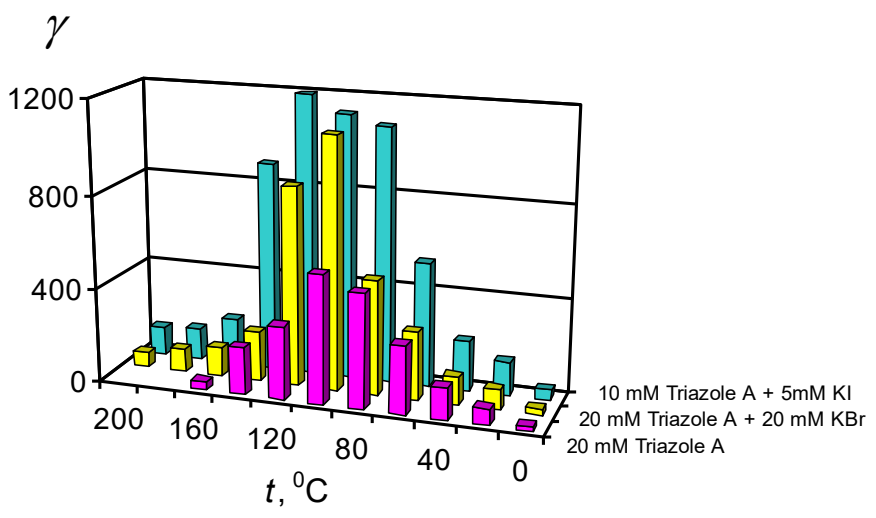

Fig. 11b. Coefficients of corrosion inhibition of mild steel in $2.0 \mathrm{M} \mathrm{H}_{2} \mathrm{SO}_{4}$ containing inhibitors. The experiment duration was $0.5 \mathrm{~h}$.

Autoclave corrosion studies in $2.0 \mathrm{M} \mathrm{H}_{2} \mathrm{SO}_{4}$ demonstrated that the steel corrosion rate increases with increasing temperature. At $t=160^{\circ} \mathrm{C}$ it attains a huge value $\left(\approx 6 \mathrm{~kg} / \mathrm{m}^{2} \mathrm{~h}\right)$ but even in this case Triazole $\mathrm{A}$ is stable and inhibits corrosion of steel. Besides, it forms synergistic mixtures with less effective inhibitors such as $\mathrm{KI}$ or $\mathrm{KBr}$. For example, when using a mixture of $5 \mathrm{mM}$ Triazole A with $5 \mathrm{mM} \mathrm{KI}$, the corrosion rate is lower than that for $10 \mathrm{mM}$ Triazole A by a factor of 7.8 and yields $Z=99 \%$. It is important that under the experimental conditions, no oxidation of $\mathrm{KI}$, which is part of the inhibitor mixture, to free $\mathrm{I}_{2}$ takes place. Our studies showed that Triazole $\mathrm{A}$ is an effective high-temperature inhibitor in various acidic solutions due to its chemisorptions on the steel surface $[27,28]$. Triazoles can also be effective corrosion inhibitors of steels in the presence of $\mathrm{H}_{2} \mathrm{~S}$ and protect steel from hydrogen pickup [29].

Among the new inhibitors, dimegin, i.e., disodium salt of 2,4-di(1-metoxyethyl)deuteroporphyrin, deserves attention [30]. Small additions of dimegin (up to $30 \mu \mathrm{mol} / \mathrm{l}$ ) not only promote the passivation of iron in neutral borate buffer by decreasing the passivation current density but also impede the local depassivation of the electrode by increasing the pit potential $E_{\text {pt }}$ (Fig. 12).

Dimegin adsorption on the passive iron from borate buffer solution results in the formation of a monomolecular layer that is firmly bound to the metal surface (Fig. 13). Small changes $\left|\delta \Delta \approx 0.41^{\circ}\right|$ on oxidized iron correspond to film thickness of $\approx 0.9 \mathrm{~nm}$, which may correspond to the almost planar location of the dimegin macrocycle. In the first approximation, the dimegin adsorption is adequately described by the Temkin equation with the considerable value of the $\left(-\Delta G_{\mathrm{A}}^{0}\right)$ :

$$
\theta=(1 / f) \ln \left(B_{\max } \mathrm{C}\right),
$$

where $B_{\max }=[1 / 55.5] \exp \left(-\Delta G_{\mathrm{A}}^{0} / R T\right)$ is the adsorption constant and $f$ is the factor of surface energy heterogeneity that characterizes the change in enthalpy of adsorption with surface coverage. The calculated value $\left(-\Delta G_{\mathrm{A}}^{0}\right)=43.3 \pm 2.6 \mathrm{~kJ} / \mathrm{mol}$ for dimegin is 
considerably larger than that for BTA $\left(-\Delta G_{\mathrm{A}}^{0}\right)=19.2 \pm 1.4 \mathrm{~kJ} / \mathrm{mol}$ whose adsorption can also be described by the Temkin isotherm.

The results of measuring the dimegin adsorption give grounds to assume that its anions are firmly chemisorbed on the oxidized iron surface. Taking this fact into consideration, along with the multicenter nature of the dimegin molecule, its simultaneous use with other corrosion inhibitors is of interest in constructing ultrathin protective films on iron or other metals and alloys.

As we have shown [31-33], an efficient way to enhance the inhibitor adsorption may involve its application on a preadsorbed layer of another chemisorbed inhibitor rather than directly on the metal. In connection with this, we also investigated feasibility of enhancing BTA adsorption with dimegin, which was used as a surface modifier. The coverage degree of the iron electrode $(\theta)$ was $0.27-1.0$.

The modification of the surface of passive iron by dimegin adsorption was carried out at $E=0.2 \mathrm{~V}$; then the solution was replaced with the pure buffer at the applied potential. After replacement of the solution, the ellipsometric angles $\Delta$ and $\psi$ remained almost constant for $2 \mathrm{~h}$, which indicates the absence of dimegin desorption and supports our hypothesis on its chemisorption on oxidized iron. To measure BTA adsorption on the surface of the modified electrode, we added concentrated BTA in portions to pure borate buffer, then measured the changes in the ellipsometric angle $\Delta$ over time. When $\Delta$ reached a constant value, we regarded it as a criterion for the equilibrium BTA adsorption.

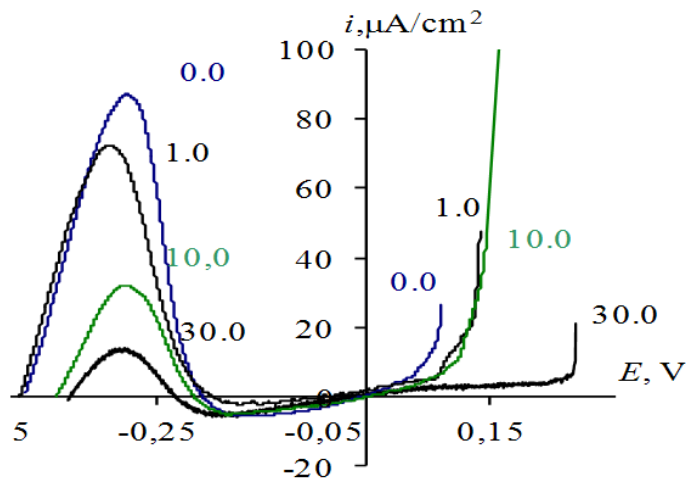

Fig. 12. Anodic polarization curves of iron in borate buffer ( $\mathrm{pH}$ 7.4) containing $0.01 \mathrm{M} \mathrm{NaCl}$ and dimegin. The dimegin concentration $(\mu \mathrm{M})$ is shown near the curves. 


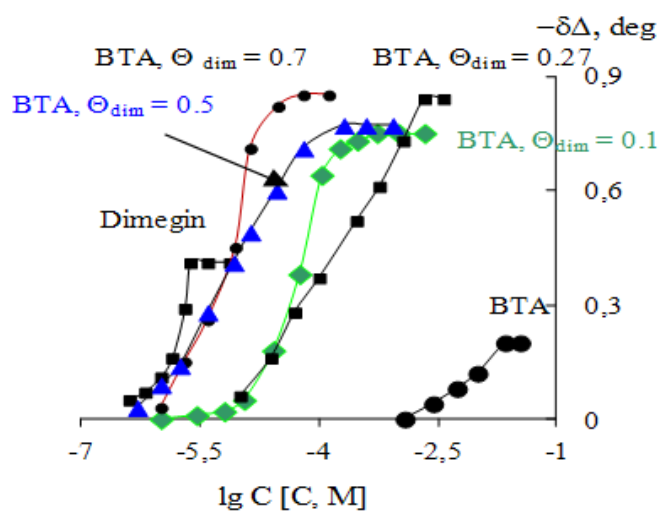

Fig. 13. Change in ellipsometric angle $\delta \Delta$ as a function of logarithm of dimegin and BTA concentration on zone-melted iron surface at $E=0.2 \mathrm{~V}$ and an iron electrode preliminarily modified by dimegin adsorption. The coverage degrees of the surface by dimegin, $\theta_{\text {dim }}$, are indicated near the curves.

The thickness of the adsorbed BTA layer significantly increases when it is formed on oxidized iron whose surface was at least partially preliminarily covered by dimegin. At all coverage degrees of dimegin, the thickness of the adsorbed BTA layer is $1.1 \pm 0.1 \mathrm{~nm}$. An increase in the thickness of the BTA adsorption layer may be stipulated by the tendency of water-soluble polar porphyrins to associate with electron-donating molecules [34]. In our case, it can result in the formation of BTA-dimegin associates. Preliminary chemisorption of dimegin obviously enhances the subsequent BTA adsorption, which is characterized by a higher value of $\left(-\Delta G_{\mathrm{A}}^{0}\right)$ (Table 2$)$.

Table 2 Adsorption characteristics of BTA upon variation in coverage degree of oxidized iron surface by dimegin

\begin{tabular}{ccc}
\hline $\boldsymbol{\theta}_{\text {DMG }}$ & $\boldsymbol{f}$ & $\left(-\boldsymbol{\Delta} \boldsymbol{G}_{\mathrm{A}}^{\mathbf{0}}\right), \mathbf{k J} / \mathbf{m o l}$ \\
\hline 0 & $3.6 \pm 0.7$ & $19.2 \pm 0.9$ \\
0.27 & $5.1 \pm 0.3$ & $38.7 \pm 1.9$ \\
0.50 & $5.0 \pm 0.5$ & $45.1 \pm 2.2$ \\
0.70 & $1.9 \pm 0.5$ & $44.6 \pm 2.2$ \\
1.00 & $4.7 \pm 0.8$ & $39.9 \pm 2.0$ \\
\hline
\end{tabular}

The adsorption parameters depend on the coverage degree of the metal surface by dimegin (Table 2). When passing to the modified surface, the factor of its heterogeneity (the $f$ value in the Temkin isotherm) first increases (to $\theta_{\mathrm{DMG}} \approx 0.5$ ), then decreases. The 
same effect on the value of $\left(-\Delta G_{\mathrm{A}}^{0}\right)$ is observed for $\theta_{\mathrm{DMG}}$; however, this value is more than two times higher than that for BTA adsorption on the nonmodified surface of passive iron, even at $\theta=1.0$.

\section{Conclusions}

1. Many heterocyclic organic compounds, e.g., various azoles, are capable of adsorption on metals with formation of strong bonds with metal surfaces. The efficiency of corrosion inhibition by these compounds depends on their chemical structure, which in many cases can be described and predicted using the linear free-energy relationship (LFER) principle. This approach also provides an understanding of the nature of chemical bonds formed by an organic inhibitor with various metals being protected.

2. Knowledge of the specifics of interaction between azoles and metal surfaces allow one to choose a promising corrosion inhibitor for complex conditions and media. For example, they can be used in chemical mechanical planarization (CMP) slurries, in which simultaneous mechanical polishing and electrochemical dissolution of planarized surface usually occur. Yet another example of a new successful use of azoles is corrosion inhibition of steel at high temperatures $\left(\geq 150^{\circ} \mathrm{C}\right)$ in mineral acid solutions.

3. New possibilities of improving the anticorrosive protection of metals are provided not only by using mixtures of some azoles with carboxylate type organic corrosion inhibitors but also by constructing bilayer nanocoatings from aqueous solutions.

4. Effective inhibitors of metal corrosion can be found among rather poorly known watersoluble macroheterocycles. Small additions of dimegin (disodium salt of deuteroporphyrin) not only promote the passivation of iron in neutral aqueous solution but also impede the local depassivation of the metal. Dimegin is firmly bound with the metal surface upon adsorption that seems to be of chemisorption nature. This offers wide possibilities for further improvement of adsorption of other heterocyclic chemical compounds due to preliminary modification of the metal surface even by small concentration of dimegin.

\section{References}

1. Yu. I. Kuznetsov and L. P. Kazansky, Russian Chemical Reviews, 2008, 77, 219.

2. Yu. I. Kuznetsov, Organic Inhibitors of Corrosion of Metals, Plenum Press, New York - London, 1996.

3. L. P. Hammett, Organic chemistry. Reaction rates, equilibria and mechanisms, McGraw-Hill Book Company, New York, 1970.

4. F. M. Donahue and K. J. Nobe, Electrochemical Soc.,1965, 112, 886.

5. V. P. Grigor'ev and V. V. Ekilik, Khimicheskaia struktura i zaschitnoe deistvie ingibitorov korrozii (Chemical Structure and Protective Action of Corrosion Inhibitors), RGU, Rostov-on-Don, 1978, p. 184 (in Russian). 
6. Yu. I. Kuznetsov, Proceedings of the $10^{\text {th }}$ Europ. Symp. on Corrosion and Scale Inhibitors, Ferrara, 2005.

7. Yu. I. Kuznetsov, L. P. Kazansky, I. A. Selyaninov, D. Starosvetski and Y. Ein-Eli, Electrochemical and Solid-State Letters, 2009, 12, no. 8, 21.

8. G. I. Bregman, Corrosion Inhibitors, Mac-Millan, New York, 1963.

9. S. Thibault and J. Talbo, Met. Corros. Ind., 1975, 50, 51.

10. M. Ohsawa and W. Suetaka, Corros. Sci., 1979, 19, 709.

11. K. G. Shattuck, J. - Y. Lin, P. Cojocatu, West. Electrochim. Acta, 2008, 53. 8211.

12. L. P. Kazansky, I. A. Selyaninov and Yu. I. Kuznetsov, Applied Surf. Sci., 2012, 258, 6807.

13. R. V. Subramanian and V. Lakshminaraynan, Corros. Sci., 2002, 44, 535.

14. D. Chadvick and T. Hashemi, Surf. Sci., 1979, 89, 649.

15. Yu. I. Kuznetsov, L. P. Kazansky, I. A. Selyaninov, D. Starosvetski and Y. Ein-Eli, Electrochemical and Solid-State Letters, 2009, 12, no. 8, 21.

16. A. Arancibia, J. Henriquez-Roman, M. A. Páez et al, J. of Solid State Electrochem., 2006, 10, no. 11, 894.

17. M. O. Agafonkina, Yu. I. Kuznetsov, N. P. Andreeva, Yu. E. Pronin and L. P. Kazansky, Korroziya: materialy, zaschita, 2011, no. 7, 26 (in Russian).

18. M. O. Agafonkina, N. P. Andreeva, L. P. Kazansky, Yu. I. Kuznetsov and Yu. E. Pronin, Korroziya: materialy, zaschita, 2012, no. 4, 9 (in Russian).

19. L. P. Kazansky, I. A. Selyaninov and Yu. I. Kuznetsov, Applied Surf. Sci., 2012, (in press).

20. Yu. I. Kuznetsov and N. P. Andreeva, Russian Journal of Electrochemistry, 2012, 48, 438.

21. L. P. Kazansky, Yu. I. Kuznetsov, N. P. Andreeva and Ya. G. Bober, Applied Surface Science, 2010, 257, 1166.

22. F. L. McCrackin, NBS Technical Note, 1969, no. 479.

23. F. Saito and K. Nobe, Corrosion, 1980, 36, no. 4, 178.

24. N. I. Podobaev and V. V. Vasil'ev, in Inhibitory korrosii metallov (Inhibitors of Metal Corrosion), MGPU, Moscow, 1969, 72 (in Russian).

25. W. W. Frenier, Proceedings of the $9^{\text {th }}$ Europ. Symp. on Corrosion and Scale Inhibitors, Ferrara, 2000.

26. Ya. G. Avdeev, P. A. Belinskii, Yu. I. Kuznetsov and O. O. Zel', Protection of metals and physical chemistry of surfaces, 2010, 46, no. 7, 782.

27. Ya. G. Avdeev, A. Yu. Luchkin, Yu. I. Kuznetsov, I. G. Gorichev and M. V. Tyurina, Korroziya: materialy, zaschita, 2011, no. 10, 9 (in Russian).

28. Ya. G. Avdeev, A. Yu. Luchkin, and Yu. I. Kuznetsov, Korroziya: materialy, zaschita, 2012, no. 9, 9 (in Russian).

29. L. V. Frolova, Yu. I. Kuznetsov, and O. O.Zel', Protection of metals and physical chemistry of surfaces, 2009, 45, no. 7, 796. 
30. Yu. I. Kuznetsov, M. O. Agafonkina, N. P. Andreeva and A. B. Solov'eva, Protection of metals and physical chemistry of surfaces, 2010, 46, no. 7, 743.

31. Yu. I. Kuznetsov and N. P. Andreeva, Protection of metals, 2005, 41, no. 6, 531.

32. Yu. I. Kuznetsov and N. P. Andreeva, Russian Journal of Electrochemistry, 2006, 42, 1101.

33. Yu. I. Kuznetsov, Protection of metals and physical chemistry of surfaces, 2011, 47, no. 7,821 .

34. T. M. Zhientaev, N. S. Melik-Nubarov, E. A. Limakovich, et al., Vysokomoleculyarnie Soedineniya, 2009, 51, no. 5, 757 (In Russian). 